\title{
Acesso e integralidade: \\ a compreensão dos usuários de uma rede de saúde mental
}

\author{
Access and comprehensiveness: the viewpoint \\ of users of a mental health network
}

Raimunda Félix de Oliveira ${ }^{1}$

Luiz Odorico Monteiro de Andrade ${ }^{2}$

Neusa Goya ${ }^{3}$

\footnotetext{
${ }^{1}$ Secretaria Municipal de Saúde de Fortaleza, Prefeitura Municipal de Fortaleza. Rua do Rosário 283/407, Centro. 60055-090 Fortaleza CE. raimundafelix@yahoo.com.br ${ }^{2}$ Faculdade de Medicina, Universidade Federal do Ceará - Campus Sobral. ${ }^{3}$ Secretaria de Gestão Estratégica, Ministério da Saúde.
}

\begin{abstract}
This article analyzes user viewpoints regarding mental health care, with a focus on comprehensiveness and access at Psychosocial Care Centers (PCCs). It is a qualitative study with theoretical and methodological references of the Fourth Generation Evaluation and application of the Hermeneutic Dialectic Circle technique. Twelve users of ten mental health services in Fortaleza were interviewed from March to May 2011. Themes of the study were grouped from the narratives, with the hermeneutics of Paul Ricoeur as the benchmark for analysis. The thematic categories were: viewpoints on mental healthcare; conflicts between supply and the subjective need to receive; similarities and differences: from tutelage to autonomy; absence and belonging: open PCCs and non-community centers; between stigma and humanization. The main findings are: the PCCs are seen as spaces for conviviality able to establish affective and social networks; stigma, prejudice and tutelage are present in the services, in their families and in the community; asylum practices persist in alternative services; the humanization of care extends access and bonding in the services; the trajectory of users of the Unified Health System occurs due to their social and health needs.

Key words Access, Comprehensiveness, Mental health, Understanding, Hermeneutics, Social and community networks
\end{abstract}

Resumo Objetivo do presente trabalho foi analisar as compreensões dos usuários dos Centros de Atenção Psicossocial sobre a atenção em saúde mental, com foco na integralidade e no acesso. Estudo de abordagem qualitativa com referencial teórico-metodológico da Avaliação de Quarta Geração e aplicação da técnica do Círculo Hermenêutico Dialético. Foram entrevistados 12 usuários de dez serviços de saúde mental de Fortaleza, de março a maio de 2011. Os temas do estudo foram agrupados a partir das narrativas, tendo como referencial de análise a hermenêutica de Paul Ricoeur. As categorias temáticas trabalhadas foram: compreensões sobre atenção em saúde mental; tempos quebrados: conflitos entre as ofertas e as necessidades subjetivas de receber; aproximações e distanciamentos: entre a tutela e autonomia; ausência e pertença: CAPS aberto e não comunitário e entre o estigma e a humanização do cuidado. Os principais achados: os CAPS são vistos como espaço de convivência capaz de estabelecer redes afetivas e sociais; estigmas, preconceitos e tutela estão presentes nos serviços, nas famílias e na comunidade; as práticas manicomiais persistem nos serviços substitutivos; a humanização do cuidado amplia o acesso e o vínculo com os serviços; a trajetória dos usuários no SUS ocorre devido às suas necessidades sociais e de saúde.

Palavras-chave Acesso, Integralidade, Saúde mental, Compreensão, Hermenêutica, Redes sociais e comunitárias 


\section{Introdução}

A lógica manicomial presente nos serviços substitutivos, como lembra Pelbart ${ }^{1}$, traz à cena as barreiras para libertação dos manicômios mentais. Estabelecer diálogo com os usuários no campo da saúde mental é muito importante. Para tanto, duas questões precisam ser redimensionadas, uma diz respeito à participação dos usuários na produção de saberes em saúde mental e sua compreensão sobre as práticas que lhe são ofertadas e, outra, concerne à integralidade na atenção em saúde mental.

Em relação à integralidade na atenção em saúde mental, tomamos como referência teórica a concepção em suas várias dimensões, compreendendo os sujeitos em sua totalidade, com base nos aspectos sociais, políticos e históricos, na relação com a família, comunidade e sociedade ${ }^{2}$.

A integralidade compreende o diálogo entre os usuários e profissionais de saúde, por meio do qual se desenham projetos terapêuticos pautados nas compreensões dos usuários e nas necessidades por ele apresentadas. Trata-se da garantia da atenção progressiva em saúde mental em uma perspectiva não só assistencial, mas também integral percebendo o usuário como protagonista e sujeito em sua totalidade.

No tocante à participação dos usuários na produção de saberes em saúde mental e sua compreensão sobre as práticas que lhe são ofertadas ressaltamos que ambas constituem a essência dos serviços substitutivos e afirmamos que não há reforma psiquiátrica sem articulação destes dois processos.

O paradigma psicossocial ${ }^{3,4}$ não pode ficar limitado à implantação de serviços substitutivos de saúde mental. A materialização da reforma psiquiátrica requer a incorporação de novos saberes e práticas elaborados sob a ótica e a participação dos usuários, sem prescindir de seu protagonismo na construção de seu projeto terapêutico, o que requer sua compreensão sobre as ações e os serviços ofertados pela rede de atenção de saúde mental.

Rompe-se, nesse sentido, com o saber psiquiátrico tradicional ${ }^{4}$, alinhando a ideia de que a reforma da atenção em saúde mental, além de incorporar as diretrizes do SUS, tem realizado a "reforma da reforma"s, demarcando um diferencial em relação às demais políticas na medida em que incorpora novos saberes e cuidados de natureza interdisciplinar, incluindo as percepções dos usuários.

A maioria dos teóricos e profissionais no campo da saúde mental, alinhados com a refor- ma psiquiátrica, concorda sobre a necessidade de superação da ideia de cura da doença mental, assumindo a perspectiva teórica de que um su-

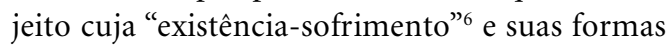
de ser e estar no mundo sejam o feixe de atenção que se abre ${ }^{3,5}$. Caso contrário, a participação e a compreensão dos usuários, comunidade e familiares sobre seu processo de saúde e doença e projeto terapêutico podem ficar limitados a eventos contingenciais, no plano da mera retórica intelectual enfatizada por Martins e Pinheiro ${ }^{7}$, sem de fato contribuir para a construção de novos saberes e práticas no campo da saúde mental.

Os processos horizontalizados, a articulação comunitária e a participação nos serviços de saúde mental se ampliam quando há o afastamento da representação do usuário como categoria funcional e individualista e ocorre a aproximação teórica e prática da compreensão relacional do cuidado em saúde ${ }^{7}$. Nessa perspectiva, os sujeitos estão em relação e não são percebidos como objetos, enquadrados numa dada definição da Classificação Internacional de Doenças (CID-10), despossuídos de um lugar, de um nome, sem possibilidade de troca. A concepção de sujeito que protagonizamos é de um cidadão com direitos e deveres, que procura conquistar autonomia e singularidade numa via de mão dupla com outros sujeitos.

Nesse sentido, faz-se necessário que a compreensão dos usuários sobre a atenção em saúde mental seja considerada no processo de formulação desta área de conhecimento, materializando o protagonismo singular destes sujeitos em relação ao campo da Saúde Mental.

A reforma psiquiátrica manifesta como movimento pressupõe a renovação e a incorporação permanente de novos saberes tecidos no processo de trabalho em saúde mental. O que requer o reconhecimento e a participação de usuários e familiares nas práticas desenvolvidas no âmbito dos serviços de saúde substitutivos.

Embora exista consenso sobre a importância do protagonismo dos usuários no SUS e no campo da saúde mental, materializada em um arcabouço jurídico-institucional, a exemplo da Carta dos Direitos dos Usuários ${ }^{8,9}$, a prática cotidiana dos serviços de saúde ainda requer a efetiva incorporação desse protagonismo.

Especialmente, as práticas de atenção em saúde mental devem considerar o direito dos usuários de compreender os processos a que estão submetidos para que a dessintitucionalização aconteça na perspectiva da integralidade, diminuindo, assim, o risco de uma nova institucionalização nas práticas de cuidado ditas substitutivas. 
O objeto do estudo orienta-se pela vertente das abordagens qualitativas, considerando que o mundo está permeado de significados e símbolos e que a intersubjetividade é um ponto de partida para captar reflexivamente os significados sociais $^{10}$. Optamos por essa abordagem por se aplicar aos estudos da história, das relações, das representações, das crenças, das percepções e das opiniões, produtos das interpretações que os humanos fazem a respeito de como vivem, sentem, pensam, constituem seus artefatos e a si mesmos ${ }^{11}$.

No processo teórico-metodológico desta pesquisa foi utilizada a Avaliação de Quarta Geração proposta por Guba e Lincoln ${ }^{12}$ e adaptada por Wetzel $^{13}$, tendo como referencial de análise os pontos de vista da hermenêutica de Paul Ricoeur ${ }^{14-16}$.

Destaca-se a compreensão dos usuários sobre a atenção em saúde mental, tendo como sujeitos do estudo usuários atendidos em dez Centros de Atenção Psicossocial (CAPS) do Tipo II ou CAPS Gerais e CAPS-AD de Fortaleza.

A construção dos dados ocorreu entre os meses de março a maio de 2011. As entrevistas foram realizadas durante dois meses, tempo suficiente para fazer uma interlocução com os serviços e se aproximar dos usuários por meio das assembleias realizadas nos CAPS. A escolha dos entrevistados para participar do Círculo Hermenêutico Dialético ${ }^{16-18}$ (CHD) foi orientada pelos critérios: i) estar há mais de seis meses sendo acompanhado nos serviços, com idade acima de 18 anos, com quadros clínicos decorrentes de sofrimento mental ou quadros clínicos decorrentes do uso abusivo de substâncias psicoativas, segundo Código Internacional das Doenças (CID 10), Transtornos Mentais e Comportamentais; ii) estar presente na assembleia dos usuários dos CAPS no momento da escolha.

A forma de escolha dos participantes da pesquisa foi acordada durante as assembleias, com os usuários presentes. Nos serviços onde não foi possível proceder a escolha nas assembleias, optamos pela participação do representante do Conselho de Saúde do CAPS. Foi garantida a representação de todas as Secretarias Executivas Regionais existentes em Fortaleza, um total de seis.

O público participante nas assembleias dos usuários nos serviços foi diverso: em algumas havia profissionais, usuários, familiares, comunidade; noutras somente usuários e apenas um profissional acompanhando; outras contavam com a presença de conselheiros de saúde; outras se confundiram com as assembleias dos CAPS, e um serviço não realizou assembleia. Embora as assembleias sejam diretrizes da organização do serviço do município, ainda não acontecem rotineiramente no cotidiano de alguns.

A aplicação da técnica do CHD possibilita o uso de adaptações à realidade. A aproximação com os participantes da pesquisa, no caso, os entrevistados, assim como as relações de troca durante as assembleias dos usuários, possibilitaram aos participantes a aproximação da compreensão sobre o tema focalizado, de acordo com a proposta da Hermenêutica ricoueuriana ${ }^{14-16}$.

No total foram realizadas 18 entrevistas, tendo sido escolhidas 12 para análise e compreensão dos dados. Utilizamos os critérios de repetição das falas e contemplamos a representação de todos os serviços municipais ao escolher as 12 entrevistas, uma de cada CAPS AD (6) e de cada CAPS Geral (6) da rede de saúde mental de Fortaleza. Mantivemos o distanciamento e o estranhamento necessários perante os dados, mas compreendendo que a subjetividade do pesquisador está presente em todas as escolhas que precisa fazer, portanto, reconhecemos que há uma via de mão dupla entre os envolvidos.

As 12 entrevistas se entrelaçaram na medida em que transcorreu a dinâmica proposta pela técnica do CHD, com os 12 usuários acompanhados sendo seis nos CAPS-Gerais e seis nos CAPS-Ad, onde foi constituído um Circulo Hermenêutico Dialético (CHD), conforme Figura 1.

Na Figura 1, o primeiro círculo pontilhado representa o grupo de entrevistados; o segundo simboliza a dinâmica do vaivém das elaborações e reelaborações teóricas (síntese de cada entrevista e por grupos). Todos os usuários do CAPSAd e do CAPS-Gerais são representados pela letra E (participante), e a síntese das entrevistas por C (construção teórica narrada).

Assim procedendo, temos na Figura 1: o resultado da primeira entrevista (El) foi apresentado ao segundo usuário, no caso, entrevistado (E2), que, após narrar as suas compreensões, recebia a síntese da entrevista anterior (C1), apresentada em forma de narrativa e, em seguida fazia seus comentários, juntando novos elementos. No caso citado, é representado por $(\mathrm{Cl})$, que já significava uma Construção Teórica Narrada 


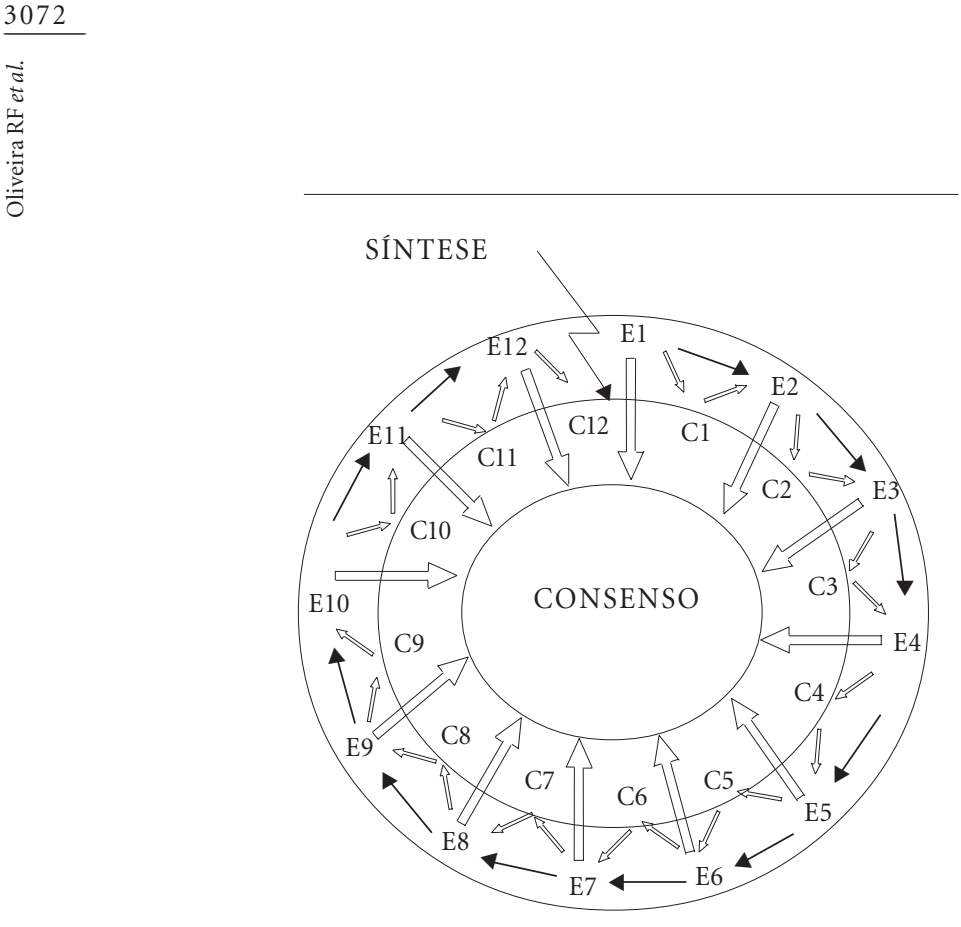

Figura 1. Círculo Hermenêutico Dialético Procedimento metodológico - $\mathrm{E}$ = entrevistado; $\mathrm{C}$ = construção teórica.

Fonte: Guba e Lincoln ${ }^{12}$

mediada pela compreensão do pesquisador e assim sucessivamente até o último entrevistado. No terceiro círculo, foram condensadas as sínteses das entrevistas, onde foram clarificadas as possibilidades de consensos ou não. Foi acordado com os entrevistados o retorno para a apresentação dos resultados.

Neste momento, fizemos as articulações com base nas falas trazidas pelos sujeitos da pesquisa, no caso, entrevistados E1 até E12, assim como descrito no Círculo Hermenêutico Dialético. Desta forma, seguimos o caminho hermenêutico de passar várias vezes pelo mesmo lugar, onde os entrevistados puderam fazer novas reflexões sobre suas falas. No momento das construções teóricas narradas (C), estava presente a subjetividade da pesquisadora, parte integrante das escolhas dos fatos narrados.

O texto torna-se, assim, implicação do entrevistado e do pesquisador, que passa a lê-lo em forma de narrativa verbal, das questões que vão surgir deste momento de partilha. Em certo sentido, o texto não mais pertence ao primeiro autor e, assim, a narrativa torna tempo atual, o tempo de quem narra e o tempo de quem se fala. É o texto narrado em forma de discurso que se torna livre da sua própria criação. O discurso é produzido como um evento e compreende-se como significação: compreender o sentido da enunciação constitui um processo circular ${ }^{14}$.
De posse da transcrição do material gravado em cada entrevista, foram realizadas as elaborações teóricas narradas (C), seguindo o referencial teórico de Ricouer ${ }^{14-16}$, para depois apresentálas aos entrevistados, na perspectiva de aproximação do consenso entre as narrativas, então tornadas textos para os usuários. As construções teóricas narradas (C) são as entrevistas transcritas em forma de narrativas escritas, que eram apresentadas ao E2 após entrevista do E1 e assim sucessivamente.

Nos processos avaliativos que envolvem usuários, eles não devem ser vistos apenas como objeto de pesquisa, mas como cocondutores, fontes de informações e de transformação da realidade. É muito importante que os sujeitos partilhem decisões, exerçam controle sobre o projeto de avaliação, apropriem-se dos diferentes passos da avaliação e tenham honradas suas participações por intermédio da interpretação hermenêutica e da compreensão dialética que buscam trabalhar os conflitos e produzir os consensos possíveis ${ }^{14}$.

A pesquisa respeitou os aspectos éticos previstos pelo Conselho Nacional de Saúde e foram garantidos o sigilo e o anonimato dos sujeitos da pesquisa por meio da utilização do Termo de Consentimento Livre e Esclarecido e pela identificação dos depoimentos pela letra "E" (usuários). O projeto de pesquisa foi aprovado pelo Comitê de Ética em Pesquisa da Universidade Federal do Ceará (UFC).

\section{Resultados e discussão}

As significações subjetivas das falas emergiram quando da finalização das transcrições decorrentes das narrativas dos usuários. No momento em que se tornaram textos escritos, representavam recortes das relações sociais e intersubjetivas $^{19}$ da vida cotidiana dos usuários, independentemente do consenso ou não das histórias descritas.

Assim, compreender não significa encontrar verdade única, mas quantas verdades apareçam e, sempre que as verdades se encontrarem, possa surgir, então, um ponto encontro em torno de uma verdade coletiva, representativa do pensamento, da vivência de todos envolvidos.

Um dos primeiros resultados encontrados refere-se ao fato das assembleias dos usuários não ter aparecido como dispositivo transversal durante todo o círculo de entrevistas. As assembleias, enquanto espaço de participação, não foi va- 
lorizada pelos usuários, estando ausente dos discursos. Não foram compreendidas como um lugar de participação, pertencimento e espaço político, evidenciando o primeiro distanciamento das diretrizes da política municipal de saúde mental.

Para dar conta das aproximações ou distanciamentos sob o olhar da compreensão dos usuários sobre a atenção em saúde mental, construímos cinco unidades temáticas, separadas por uma questão de clareza metodológica, mas entendendo que todas fazem parte de uma unidade.

\section{As compreensões sobre atenção em saúde mental}

Para os usuários, as compreensões sobre a atenção em saúde mental se materializam numa atenção acolhedora, humanizada e de aceitação das condições subjetivas, sociais e espirituais, transcritas nas suas histórias de vida.

De fato, questões estruturais como falta de alimentação e vales transporte, material de oficinas, limpeza das piscinas, carros para visitas domiciliares e falta de profissionais são importantes e são reivindicadas, mas não aparecem como sendo prioritárias, como fundamentais, na forma como compreendem a atenção. São fatores que ampliam o acesso aos serviços, mas não são determinantes. Para os usuários, a liberdade e as possibilidades de fazer escolhas, são os aspectos mais significativos.

Todas as formas de manipulação, tutela e estigma, sejam de profissionais, familiares, vizinhos e comunidades são consideradas como não atenção em saúde mental, sendo mais significativo o sentimento de pertença e aceitação das singularidades. Trata-se da posse de um novo social para a loucura ${ }^{20,21}$.

A fala a seguir expressa as compreensões acima relacionadas:

o que me pega aqui é a fraternidade, porque eu não reclamo porque não tomo um cafezinho numa mesa. [...] me deram tanta fraternidade e eu chego até dizer pra doutora que lá fora durante a primeira vida, segunda vida, terceira vida e a atual eu nunca tive tanta fraternidade como estou tendo aqui, não é babando não, é a verdade. (E6).

A preferência por ficar acolhido nos serviços do CAPS tem relação com as dificuldades sentidas de participação das atividades na comunidade, evidenciando o não exercício de direitos sociais coletivos. A compreensão da atenção em saúde mental deve possibilitar ao usuário sua atuação como sujeito da comunidade ${ }^{22}$, sujeitos reflexivos e operativos ${ }^{23}$.
Segundo as falas, manteve-se como demanda constante a garantia de acesso mais continuo, caracterizando a necessidade de uma permanência mais intensiva nas redes de atenção seja do SUS ou de outros pontos de apoio, objetivando a garantia de direitos integrais, principalmente, na perspectiva da geração de renda.

Neste sentido, embora tenha sido garantido o acesso a uma rede de atenção em saúde mental, a vulnerabilidade social retroalimenta a atenção psicossocial para dentro dos serviços:

Ah! você tem que sair daqui, tudo bem tem que sair que a gente não vai ficar a vida toda no CAPS, mas para isso, para motivar o pessoal tinha que ter um curso profissionalizante tipo assim mecânica. Eu achava legal que o CAPS fizesse uma parceria com o com o SINE. (E7).

A ideia do CAPS como a segunda casa, foi outra temática bastante enfatizada. Como casa afetiva, um lugar onde as pessoas recebem ajuda, mas principalmente como lugar de troca de afetos e de apoio entre eles mesmos:

Sou mais apoiado aqui do que em casa. Vamos dizer que o CAPS é a minha segunda casa. (E5).

De certa forma, grande parte da rede social destes usuários fica restrita ao lugar de tratamento. Para a maioria deles, os vínculos se restringem às redes de relações com os outros usuários e profissionais dos CAPS, além de outras pessoas como a vendedora de café que fica em frente à unidade, o motorista do ônibus da sua linha, o motorista do carro das visitas domiciliares, enfim, as pessoas que estão na circularidade dos serviços.

Outra constatação foi que o distanciamento e a rejeição das famílias para alguns, é compensado pelo afeto recebido nos serviços. Compreendem que os profissionais podem responder a esta demanda afetiva no cotidiano dos serviços, havendo uma expectativa de presença afetiva constante e compensadora das necessidades subjetivas. O suporte afetivo e terapêutico das famílias é bastante significativo para os usuários que não querem acessar os CAPS.

As falas a seguir manifestam tal compreensão:

de a gente aprender mais as coisas, pra gente parar de se lembrar das coisas do passado. Tem hora que eu penso em desistir. Quando amanhece o dia, eu venho pro CAPS, lá tem amigo, dá pra conversar com algumas pessoas, está acontecendo isso comigo. (E5).

Me sinto bem, aqui é uma família, se eu estou mal elas chegam junto. Então foi aqui onde eu encontrei pessoas que realmente me ajudaram. To- 
das, não tiro nenhuma, do faxineiro até a coordenadora. (E11).

Minha família comigo, desabafando porque lá fora eu não tinha ombro pra chorar e aqui eu tenho ombro pra me apoiar e eu tenho onde me apoiar, o CAPS pra mim é uma ponta de apoio, eu não posso falar pelas outras pessoas, eu sempre falo por mim. (E6).

\section{Os tempos quebrados: conflitos entre as ofertas e as necessidades subjetivas de receber}

Nomeamos de tempos quebrados os discursos contraditórios entre o que é ofertado como a atenção por parte dos profissionais, e, por outro lado, como essas ações e atitudes são compreendidas pelos usuários.

Diante da demanda afetiva-social não correspondida, por parte dos profissionais, surgem situações conflituosas. Relatam sentimentos de estigmatização das famílias e da comunidade para com os usuários que são portadores de sofrimento mental e ou que fazem uso abusivo de drogas, independentemente de serem atendidos no CAPS, no hospital psiquiátrico, nos hospitais gerais e ou acolhidos em comunidades terapêuticas etc. Antes eram chamados de loucos por se internarem nos hospitais psiquiátricos, e agora são também chamados de loucos por serem acompanhados nos CAPS. Para Ricouer ${ }^{15}$, nestes momentos, ocorre a dialética de sentido e de referência, onde precisamos compreender a zona de tempo que dá significado ao discurso, tentando conceder visão pública às metáforas, aos símbolos e à linguagem.

A fala a seguir manifesta o exposto acima:

porque eu acho que quando a pessoa assume um compromisso de ser terapeuta na área da saúde mental ela tem que saber lidar com os transtornos da gente, porque se a gente procura o CAPS a gente vem em busca de socorro, então é pra gente ter respeito dentro do serviço, entendeu, não é pra gente ser maltratada nem nada. (E4), (Retorno).

Os usuários fazem a associação da atenção em saúde mental ao serviço CAPS, como alternativa clara ao modelo asilar ${ }^{19}$ :

eu acredito que no CAPS você possa vir fazer o tratamento e os portões estão abertos pra que você venha, faça o tratamento e volte pra sua casa e tenha aquele horário que você participa dos grupos, das terapias, do atendimento individual com o psicólogo, com as terapeutas ocupacionais e aí você paralelamente com a sua medicação tem esse acompanhamento e ele dá uma ideia de casa, ela não tem aquela mistificação de que seja aquela coisa fechada, presa e que você fica internado atrás de umas grades fechadas. (E8).

$\mathrm{Na}$ proposta do modo psicossocial, temos como características a interdisciplinaridade, possibilidades de trocas com os usuários e familiares, apropriação dos espaços da comunidade, ser aberto à participação comunitária nos serviços, a corresponsabilidade dos usuários nos projetos terapêuticos acordados distanciando-se de relações tuteladas e buscando uma cidadania conquistada.

\section{Aproximações e distanciamentos entre tutela e autonomia}

Para Ricouer ${ }^{14}$, uma das articulações possíveis são as interfases de apropriação e distanciação.

A questão é que, no cotidiano das práticas em saúde mental, ocorrem conflitos nos processos das relações horizontalizadas entre os agentes envolvidos. Claramente, nas falas, está o entendimento de que a atenção não deveria ser de maneira imposta, tutelada, exercida pelo poder dos profissionais sobre os usuários:

ai a gente chega atrasado, ai não bota o almoço porque a gente não chega na hora. (E1).

Eles ficam pressionando. Você tem que fazer isso, você tem que fazer aquilo e não sei o que, também isso eu acho errado porque eu acho que cada coisa é no seu tempo, a gente não pode ser obrigada a fazer nada até porque a gente tem o livre arbitrio de ir e vim. (E4) (Retorno).

Uma reflexão necessária refere-se ao fato de que a tutela e o controle podem ser uma formulação incorporada nos projetos terapêuticos, que os profissionais acordaram para os usuários, sem de fato ser discutida a corresponsabilização. E mesmo que o profissional acredite que esta fazendo o melhor pelo usuário, no momento em que não há o acordo terapêutico claro e a escuta qualificada dos usuários, geram-se conflitos, sentimentos de ser tutelado, ser segregado da participação, enfim, ser novamente excluído. Estes são os riscos que os serviços substitutivos precisam evitar sob pena de reescrever uma nova roupagem para os manicômios mentais, lembrado por Pelbart ${ }^{1}$, que distanciam a efetiva atenção em saúde mental.

Segundo o usuário:

Você não pode sair no portão sem a ordem deles, você não pode falar alto que meu, que meu jeito de falar alto é esse, falar alto, ficam brigando, fala mais baixo. [...] ninguém pode fazer um tantim assim, que ela fica no pé do ouvido dos outros. Se 
fizer um pouquinho ela já corta o almoço. Ninguém gosta dela aqui dentro, porque ela quer ser muito mandona. (E1).

Na mesma direção, reconhecemos que é necessário formular mudanças nas comunidades, problematizar os conflitos, visto que ainda permanece pouco visível a condição de cidadania do "louco".

Qual seria o lugar da autonomia dentro de um serviço que se propõe aberto e comunitário? Deveria ser um serviço capaz de impulsionar estratégias que possibilitassem autonomia, participação e liberdade de escolhas. Para os usuários dos CAPS, isto ainda não acontece, pois os próprios profissionais de saúde desencadeiam, dentro dos serviços, atitudes de tutela em relação aos usuários:

Eles têm muita autonomia como ela mesmo relatou. A gente está sempre sendo obrigada a seguir as regra deles. Tem que ser como eles querem. Se há um passeio e a gente não quer ir eles ficam comentando que a gente não foi por isso e por aquilo, sem realmente saber nem o que está acontecendo. (E4.) (Retorno).

Os usuários avaliam como uma boa atenção em saúde mental, aquela em que eles possam fazer escolhas, opinar e participar quando as ações propostas façam sentido para eles. A participação forçada nas atividades desenvolvidas nos serviços, a falta de clareza dos seus próprios projetos terapêuticos e os autoritarismos dos profissionais, são causadores de sentimentos conflituosos, enfim, sofrimento psíquico para os usuários.

Os usuários apontaram dificuldades em entender as singularidades dos projetos terapêuticos, fato que os distanciam da permanência nos serviços:

às vezes eu me sinto um ping-pong, se eu sair do grupo, ela fica com raiva. Já passou uma semana sem falar comigo. (E3) (Retorno).

\section{Ausência e pertença \\ - CAPS aberto e não comunitário}

As redes sociais de apoio de outros níveis de atenção intersetorial ainda não aparecem de forma transversal nas falas dos usuários, limitando-se ao acesso dentro do campo da saúde.

Uma face desta questão diz respeito à circularidade pela cidade e a trajetória do usuário nos sistemas, que acontece de forma muito tímida e balizada pela perspectiva de uma cidadania regulada e institucionalizada em detrimento de uma das principais diretrizes dos serviços substitutivos, que é operar na perspectiva da desinstitucionalização, decorrente do fato de os serviços não conseguirem incorporar as ações comunitárias no território de maneira transversal e nem se alinhar com a proposta da clínica ampliada ${ }^{23}$.

Esta transição só faz sentido para os usuários quando os mesmos serviços são capazes de propor opções de convivência e circularidade. Não basta a garantia de acesso interno aos serviços para se construir uma atenção integral. Para os usuários que têm um tempo ampliado no serviço CAPS, quando seus projetos terapêuticos indicam a continuidade da atenção e cuidado em outras redes do sistema de saúde ou nas redes dos demais sistemas de apoio, é motivo para desencadear sofrimento psíquico.

Para os usuários, os CAPS são espaços que permitem troca entre pares, principalmente pelo fato de redes sociais de apoio não absorverem estas demandas:

há convivência, que meu maior medo é de convivência, com a comunidade, pelo que eu passei, pelo jeito das pessoas olharem pra gente, isso me deixa com ... às vezes eu estou num lugar, as pessoas julgam a gente pelo modo que a gente se veste. (E2).

Tem uma menina do grupo de sexta, a Marieta, no mesmo grupo tem a Marilia que a gente fala, se encontra e sai fora aqui do CAPS, eu conheci elas no grupo, a Marilia namorando alguém do mesmo grupo, a Marieta e deixou o namorado e ela dá em cima de mim ou eu dou em cima dela, não sei, aí nós quatro às vezes saímos e a gente se conheceu tudo no mesmo CAPS. (E8).

Mas quando souberam que eu tive uma crise maior, aí que eles se afastaram mesmo e tal e hoje em dia eu já consigo, mudou, mudou e pra melhor porque esse tratamento que eu faço eu tomo minha medicação, eu venho para os grupos e aí eu já consigo conviver socialmente sem trazer prejuizos nem pra mim e nem para a pessoa que está próxima a mim. (E10).

Sintetizamos esta situação crítica numa expressão 'tempo para não institucionalizar'. Seria um tempo no qual os projetos institucionais dos serviços estivessem alinhados aos projetos terapêuticos singulares dos usuários, para que aqueles, com perfil de alta da atenção psicossocial no CAPS, fossem visto de forma integrada. Nominamos "tempo não institucional" como aquele em que os profissionais, por meio dos projetos terapêuticos, avaliassem o momento de mudar as modalidades de atenção no serviço, ou fora dos serviços CAPS, ou o tempo em que o próprio usuário, de forma partilhada, refletisse sobre o momento da sua travessia.

Os usuários protagonizam a importância do momento de desvinculação dos serviços sem, contudo relacionar tal fato à vinculação com as 
famílias, amigos, comunidade ou com alguma outra rede ou ponto de apoio social:

conversando com meu neto, eu disse: meu filho, o velho aqui não tem mais condição de melhorar de vida financeiramente porque eu não tenho como trabalhar e hoje tudo gira em torno da juventude e a verdade é essa mesmo: velho é pra ser encostado ou viver comendo mosca e deitando na espreguiçadeira, queimando aquele cigarro, velho fumo. Veja seu avô, aqui acolá tá entrando numa droga. O seu avô não deixa mais, o avô só quer viver queimando droga. (E6).

$\mathrm{O}$ acesso aos serviços acontece através das famílias, amigos, instituições. A permanência nos serviços ocorre pelas possibilidades de trocas horizontalizadas ${ }^{19}$ com outros usuários e também com os profissionais que têm algum tipo de vínculo, e, na perspectiva deles não estão sendo 'institucionalizados', mas estabelecendo relações entre os pares:

então eu tenho eles aqui como irmãos, como amigos, me entristece quando eu os vejo na rua, aquilo ali é um sofrimento pra mim, aí hoje eu quero, peço meu filho deixe isso aí. (E11).

É melhor estar aqui do que onde eu convivo. (E12).

A compreensão da atenção em saúde mental como uma potência para fazer o entrelaçamento na comunidade e adentrar a vida comunitária, aparece de forma significativa na fala de todos os entrevistados:

Ah, o que mudou em mim é que eu aprendi a conviver mais de cabeça erguida, porque, mesmo tendo problema, eu sei que posso viver dentro da comunidade, posso me socializar com as pessoas, isso prá mim, deu um novo rumo de vida, porque eu acho que eu não tinha, não tinha que viver naquela, naquela lombra, naquela lombra, naquela lombra, naquela outra lombra, e assim ia, quando não era lombra, era bebida e assim a vida ia, não tinha pra que, porque viver. (E2).

Outra fala também expressa esta mesma compreensão:

agora eu vivo bem, tranquila e já vou pra missa na igreja todo domingo, participo, estou fazendo curso bíblico, estou fazendo hidroginástica, minha vida está uma maravilha. Ave Maria em comparação ao que eu vivia está um paraíso. É muito bom, você está limpa e você não está com aquela agonia, aquele desespero de estar numa boca de fumo usando uma droga. Ave Maria é horrível, horrivel, todo dinheiro que você pega é pra comprar, Ave Maria é um desespero. (E9).

\section{Entre o estigma e a humanização do cuidado}

A questão do estigma, do preconceito, dos sentimentos de exclusão e isolamento, foi também recorrente nas narrativas permeado pelo sentimento de desvalorização pelo outro, desrespeito aos seus direitos de cidadão, assim como a compreensão de estarem despossuídos de várias relações que a sociedade oferta, por exemplo, as trocas entre pares, familiares e vizinhos, conforme se identifica na fala a seguir.

Ai eu boto a cadeira lá fora ai fico, pego um rádio que eu tenho, ai fico sentado escutando música agora, ai fico até nove horas, até na hora de tomar o comprimido, não chega ninguém prá conversar comigo, é todo pra lá, se souber que eu tenho esse problema, ai ninguém chega pra conversar comigo, só quem chega e vão à minha casa às vezes é o M., a P., o A., o D. , questão de amigos são poucos e família só tem uma que cuida de mim, que não tem medo. (E5).

Outro ponto que aparece é o reconhecimento dos estigmas e preconceitos que os próprios usuários manifestaram em relação a eles mesmos e aos demais usuários dos serviços. As falas sinalizaram que o tempo vai fortalecendo as relações, ampliando as possibilidades de compreensão destas questões, indicando a urgência de pensar estratégias intersetoriais que problematizem a cultura manicomial.

As falas a seguir expressam tal fato:

Porque eu falei assim, a questão de quando eu vejo um usuário aqui do CAPS em qualquer outro lugar, eu falo. Tem gente que não fala, ainda gera aquele preconceito, porque faz tratamento no CAPS e eu não vou falar pra não dizer que eu também faço, mas não, hoje em dia eu não tenho esse problema. (E8).

Quando amanhece o dia, eu venho prá cá, porque na rua a gente passa e as pessoas chamam a gente de doido, olha o tanto de comprimido, ruma de comprimido, olha o doido, bicho otário vai pro hospital no meio de uma ruma de doido, desse jeito eles dizem com a gente, coisa ruim de dizer. (E12).

Sempre digo aqui no CAPS que não peço nada a ninguém, porque se torna assim uma cobrança. Eu ganhei um móvel daquele ali e vou chegar e vou pedir uma coisa a ele que tenho direito e vai passando e eu vou chegar e vou pedir, aí vai e fica a discriminação aumentando mais ainda. (E12).

Os usuários relatam que ainda sofrem muitos preconceitos, são estigmatizados pela famí- 
lia, vizinhança, comunidade em geral e por alguns profissionais que trabalham na saúde, seja nas demais redes assistenciais, nos próprios CAPS ou nas redes de serviços públicos em geral, conforme fala a seguir:

discriminação, eu senti como se nós fossemos uns bichos, por causa de uma pessoa que ficava pedindo às pessoas que passavam. Então as pessoas olhavam pra nós como se fossemos assim umas pessoas descartáveis do mundo. (E12). (Retorno).

Um homem de sessenta anos de idade que já passou pelo o que já passei, repudio de família, pisada mesmo, rebeldemente pisando 'Tu não vale nada, tu é um safado'. (E7).

Não se entregar, pois quando você desiste de cuidar de uma pessoa que tem transtorno mental, praticamente você tá abandonado. Então o que acontece? O primeiro refúgio que a pessoa tenta é o suicídio, entende? (E4).

\section{Considerações finais}

A escolha do referencial teórico-metodológico da Avaliação de Quarta Geração contribuiu para o protagonismo dos usuários durante toda a pesquisa, pois permitiu um movimento de participação e inclusão no processo analisado.

Sob a ótica da compreensão dos usuários, a ampliação do acesso aos serviços substitutivos em saúde mental, mesmo com as dificuldades estruturais, é importante, mas não determinante na avaliação dos serviços. Para os usuários, a liberdade, as possibilidades de fazer escolhas, o cuidado humanizado, a aceitação e as práticas não manicomiais, são os aspectos mais significativos na análise da atenção em saúde mental.

Em decorrência das dificuldades dos serviços, comunidade e sociedade civil em propor opções de convivência e circularidade na cidade, os CAPS funcionam como lugar de proteção afetivo-social, sendo fundamental o uso de estratégias de corresponsabilização nos projetos terapêuticos singulares, visando à integralidade da atenção em saúde mental.

A imersão na comunidade e a construção de trajetórias que possibilitem a reinserção social são enfatizadas pelos usuários. Portanto, as políticas públicas de saúde mental precisam estabelecer estratégias que ancorem as articulações comunitárias, tencionem as discussões em torno dos estigmas, seja do louco ou do usuário de drogas, fatores determinantes para atingir uma saúde comunitária ${ }^{22}$.

As possibilidades de integralidade na atenção em saúde mental passam pelas trajetórias reais dos usuários nos sistemas de saúde, ou nos serviços intersetoriais. A integralidade deve ser construída tendo como referência as necessidades sociais, afetivas e espirituais dos usuários e não em função das ofertas de cuidado dos serviços. $O$ que reitera a urgência das políticas públicas em saúde mental de ofertar uma rede de atenção ampliada, capaz de possibilitar vinculação, problematizar a cultura manicomial, viabilizar a inserção social e a apropriação da comunidade.

Reconhecemos, assim, a necessidade de qualificar o acesso aos serviços de saúde mental, compreendendo que não basta ampliar a oferta, mas há de se compreender pelo olhar dos usuários suas efetivas necessidades em saúde, percebendo-as em sua totalidade.

Essa avaliação demonstra que sem a apropriação ou o conhecimento das compreensões dos usuários sobre a atenção em saúde mental, não é possível aos sujeitos usuários assumirem o seu protagonismo para a efetivação de uma atenção em saúde mental que coadune com os princípios e diretrizes do Sistema Único de Saúde e com os pressupostos da reforma psiquiátrica.

\section{Colaboradores}

RF Oliveira trabalhou na concepção, metodologia, análise e interpretação dos dados do estudo e na redação do artigo. LOM de Andrade contribui com a concepção, metodologia, análise e interpretação dos dados do estudo. N Goya trabalhou na redação e revisão crítica do artigo. 


\section{Referências}

1. Pelbart PP. A Nau do Tempo Rei: sete ensaios sobre o tempo da loucura. Rio de Janeiro: Imago; 1993.

2. Mattos RA. A integralidade na prática (ou sobre a prática da integralidade). Cad Saude Publica 2004; 20(5):1411-1416.

3. Amarante PCD. Saúde mental e atenção psicossocial. Rio de Janeiro: Editora Fiocruz; 2007.

4. Amarante PCD. A (clínica) e a Reforma Psiquiátrica. In: Amarante PCD, organizador. Archivos de saúde mental e atenção psicossocial. Rio de Janeiro: Nau; 2003. p. 45.

5. Campos RO, Furtado JP, Passos E, Benevides R. Pesquisa Avaliativa em saúde mental: desenho participativo e efeitos da narratividade. São Paulo: Aderaldo \& Rothschild; 2008.

6. Rotelli F, Leonardes O, Mauri D. Desinstitucionalização. 2a Edição. São Paulo: Hucitec; 2001.

7. Martins PH, Pinheiro R. Usuários, redes sociais, mediações e integralidade em saúde. Rio de Janeiro: CEPESC-IMS, UERJ, Editora Universitária; 2011.

8. Brasil. Ministério da Saúde (MS). Carta dos direitos dos usuários da saúde. Brasília: MS; 2006. (Série F. Comunicação e Educação em Saúde).

9. Carta de Direitos dos usuários e familiares da luta antimaniomial. III Encontro Nacional de entidades de usuários e familiares da luta antimanicomial. São Paulo, Santos; 1993

10. Minayo MCS. O desafio do conhecimento: pesquisa qualitativa em saúde. 7a Edição. São Paulo, Rio de Janeiro: Hucitec, Abrasco; 2000.

11. Minayo MCS. A utilização do método qualitativo para a avaliação de programas de saúde. In: Campos RO, Furtado JP, Passos E, Benevides R. Pesquisa avaliativa em saúde mental: desenho participante e efeitos da narrativa. São Paulo: Aderaldo \& Rothschild; 2008. p.15-19.

12. Guba E, Lincoln Y. Fourth Generation Evaluation. Newbury Park: Sage; 1989.

13. Wetzel C. Avaliação de serviço em saúde mental: a construção de um processo participativo [tese]. Ribeirão Preto: Universidade de São Paulo; 2005.

14. Ricouer P. Teoria da Interpretação. Rio de Janeiro: Edições 70; 2009.

15. Ricouer P. Tempo e narrativa. São Paulo: Editora WMF Martins Fontes; 2010.
16. Ricouer P. Interpretação e ideologias. 4a Edição. Rio de Janeiro: Livraria Francisco Alves Editora; 1990.

17. Oliveira MM. Como fazer pesquisa qualitativa. Rio de Janeiro: Vozes; 2008.

18. Kantorski LP, Wetzel C, Oischowsky A, Jardim VMR, Bielemann VLM, Schneider JF. Avaliação de quarta geração - contribuições metodológicas para avaliação de serviços de saúde mental. Interface Comun Saúde Educ 2009; 13(31):1-12.

19. Costa-Rosa A. O modo psicossocial: um paradigma das práticas substitutivas ao modo asilar. In: Amarante P, organizador. Ensaios: subjetividade, saúde mental, sociedade. 2a Edição. Rio de Janeiro: Ed. Fiocruz; 2008.

20. Vasconcelos EM. Reinvenção da Cidadania, Empowerment no campo da Saúde Mental e Estratégias Políticas no Movimento de Usuários. In: Amarante P, organizador. Ensaios: subjetividade, saúde mental, sociedade. 2a Edição. Rio de Janeiro: Ed. Fiocruz; 2008.

21. Lobosque AM. Clínica em Movimento: Por uma sociedade sem manicômios. Princípios para uma clínica antimanicomial. Rio de Janeiro: Garamond; 2003.

22. Góis CW. Saúde Comunitária - pensar e fazer. São Paulo: Editora Hucitec; 2008.

23. Campos GWS. Clínica e Saúde Coletiva compartilhadas: teoria paideia e reformulação ampliada do trabalho em saúde. In: Campos GWS, Minayo MCS, Akerman M, Drumond M, Carvalho YM. Tratado de Saúde Coletiva. São. Paulo, Rio de Janeiro: Hucitec, Ed. Fiocruz; 2006. p. 53-92.

Artigo apresentado em 30/04/2012

Aprovado em 17/07/2012

Versão final apresentada em 30/08/2012 